\title{
On the concavity of the consumption function with the time varying discount rate
}

\author{
Liutang Gong a,*, Ruquan Zhong ${ }^{\mathrm{b}}$, Heng-fu Zou ${ }^{\mathrm{c}, \mathrm{d}}$ \\ a Guanghua School of Management, Peking University, Beijing, 100871, China \\ b Institute of Applied Mathematics, AMSS, CAS, Beijing, 100190, China \\ ${ }^{\mathrm{c}}$ Institute for Advanced Study, Wuhan University, Wuhan, 430072, China \\ ${ }^{\mathrm{d}}$ CEMA, Central University of Finance and Economics, Beijing, 100081, China
}

\section{A R T I C L E I N F O}

Article history:

Received 21 April 2010

Received in revised form

20 April 2012

Accepted 25 April 2012

Available online 3 May 2012

JEL classification:

E21

C6

D91

Keywords:

Consumption function

Concavity

Risk tolerance

\begin{abstract}
A B S T R A C T
In this paper, we consider a finite-horizon model with the time-additive utility and the time varying discount rate. With the assumption of the concavity of absolute risk tolerance, the concavity of the consumption function has been proved. This result significantly broadens the conclusion of Carroll and Kimball (1996) for the case of the HARA utility function.
\end{abstract}

(C) 2012 Elsevier B.V. All rights reserved.

\section{Introduction}

Since Keynes (1936), many economists have had the intuition that the marginal propensity to consume out of wealth declines as wealth increases. In an early important paper, Zeldes (1989) has utilized numerical methods to find that introducing labor income uncertainty has made the consumption function concave, with the marginal propensity to consume everywhere higher than in the certainty case. If the intertemporally separable period utility function is drawn from the class of the HARA functions (hyperbolic absolute risk aversion), Carroll and Kimball (1996) have shown that the consumption function is concave. Kato and Nishiyama (2002) have also proved the concavity of the consumption function with a quadratic utility with liquidity constraints. Furthermore, Morris (2002) has presented the continuity of consumption rules with non-exponential discounting. He tackles the problem in a three

\footnotetext{
We are indebted to Dr. Wang Yaping for his helpful comments. All remaining errors are our own. This research was sponsored by the National Science Foundation for Distinguished Young Scholars (70725006).

* Corresponding author. Tel.: +86 106275 7768; fax: +86 1062751463

E-mail address: ltgong@gsm.pku.edu.cn (L. Gong).
}

period problem with non-exponential discounting and shows that, if absolute risk tolerance is concave, then the marginal propensity to consume is decreasing with wealth. Moreover, if absolute risk tolerance is convex, then the marginal propensity to consume is increasing with wealth.

Our paper is to consider a finite-horizon model with the time-additive utility and the time varying discount rate. With the assumption of the concavity of absolute risk tolerance, the concavity of the consumption function has been proved for far more general utility functions than the case of the HARA utility in Carroll and Kimball (1996).

\section{The model}

Following Carroll and Kimball (1996), we consider an intertemporal choice model. The consumer maximizes the time-additive present discounted value of utility from consumption, namely,

$V_{t}\left(w_{t}\right)=\max _{c_{t}}\left\{u\left(c_{t}\right)+\sum_{s=t+1}^{T}\left(\prod_{j=t+1}^{s} \beta_{j}\right) u\left(c_{s}\right)\right\}$

subject to

$w_{t+1}=R_{t+1}\left(w_{t}-c_{t}\right)+y_{t+1}$,

$c_{T} \leq w_{T}$, 
where $R_{t} \in(0, \infty)$ and $\beta_{t} \in(0, \infty)$ are the gross interest rate and the time preference factors, respectively; $w_{t}$ is the consumer's gross wealth, and $y_{t}$ is labor income; $c_{t}$ is the level of consumption, $u(c)$ is the instantaneous utility function, and satisfies $u^{\prime}()>$. and $u^{\prime \prime}()<$.0 .

The recursive problem associated with the above optimization problem is

$V_{t}\left(w_{t}\right)=\max _{c_{t}}\left\{u\left(c_{t}\right)+\beta_{t+1} V_{t+1}\left(R_{t+1}\left(w_{t}-c_{t}\right)+y_{t+1}\right)\right\}$.

For convenience, we define $\phi_{t}\left(s_{t}\right)=\beta_{t+1} V_{t+1}\left(R_{t+1} s_{t}+y_{t+1}\right)$, where $s_{t}=w_{t}-c_{t}$ is the portion of period $t$ resources saved.

Therefore, we have

$V_{t}\left(w_{t}\right)=\max _{c_{t}}\left\{u\left(c_{t}\right)+\phi_{t}\left(w_{t}-c_{t}\right)\right\}$

and the first-order condition

$u^{\prime}\left(c_{t}\right)=\beta_{t+1} R_{t+1} V_{t+1}^{\prime}\left(w_{t+1}\right)$.

By the envelope theorem, we have

$V^{\prime}\left(w_{t}\right)=\beta_{t+1} R_{t+1} V_{t+1}^{\prime}\left(w_{t+1}\right)$.

Thus, it is clear that

$u^{\prime}\left(c_{t}\right)=V^{\prime}\left(w_{t}\right)$.

Following Gollier (2001), an individual's absolute risk tolerance $T(x)$ is defined as the inverse of his absolute risk aversion

$T(x)=-\frac{u^{\prime}(x)}{u^{\prime \prime}(x)}$

and we obtain

$T^{\prime}(x)=-1+\frac{u^{\prime \prime \prime}(x) u^{\prime}(x)}{u^{\prime \prime}(x)^{2}}$.

Note that linear absolute risk tolerance is equivalent to the assumption that has hyperbolic absolute risk aversion (HARA). HARA utility functions imply concave consumption functions has been shown in Carroll and Kimball (1996). Here, we want to prove the following result for general utility functions.

Proposition 1. If absolute risk tolerance is concave (i.e., $T^{\prime \prime}() \leq$.0 ) and $\beta_{t} R_{t}>1$, then the optimal consumption rule is concave.

To prove this proposition, we need to prove the following three lemmas.

Lemma 1. If $\beta_{t} R_{t}>1$, then the optimal consumption level satisfies $c_{t}<c_{t+1}$.

Proof. According to the first-order condition (5) and the envelope theorem, it is obvious that

$u^{\prime}\left(c_{t}\right)=V^{\prime}\left(w_{t}\right)$

Therefore, we have arrived at

$u^{\prime}\left(c_{t}\right)=\beta_{t+1} R_{t+1} u^{\prime}\left(c_{t+1}\right)$.

Note that $\beta_{t+1} R_{t+1}>1$ and $u^{\prime \prime}\left(\right.$.) $<0$; hence, we have $c_{t}<$ $c_{t+1}$.

And from the definition of the function $\phi_{t}\left(s_{t}\right)$, we obtain:

Lemma 2. At the optimal consumption level, we have $\frac{\phi_{t}^{\prime \prime \prime}\left(s_{t}\right) \phi_{t}^{\prime}\left(s_{t}\right)}{\phi_{t}^{\prime \prime}\left(s_{t}\right)^{2}}=$ $\frac{V_{t+1}^{\prime \prime \prime}\left(w_{t+1}\right) V_{t+1}^{\prime}\left(w_{t+1}\right)}{V_{t+1}^{\prime \prime}\left(w_{t+1}\right)^{2}}$.

Proof. The proof can be obtained by a simple calculation.
Lemma 3. If absolute risk tolerance is concave and $\beta_{t} R_{t}>1$, then

$\frac{V_{t}^{\prime \prime \prime}\left(w_{t}\right) V_{t}^{\prime}\left(w_{t}\right)}{V_{t}^{\prime \prime}\left(w_{t}\right)^{2}}>\frac{u^{\prime \prime \prime}\left(c_{t}\right) u^{\prime}\left(c_{t}\right)}{u^{\prime \prime}\left(c_{t}\right)^{2}}$

for $t=0,1,2, \ldots, T-1 ;$ and

$\frac{V_{T}^{\prime \prime \prime}\left(w_{T}\right) V_{T}^{\prime}\left(w_{T}\right)}{V_{T}^{\prime \prime}\left(w_{T}\right)^{2}}=\frac{u^{\prime \prime \prime}\left(c_{T}\right) u^{\prime}\left(c_{T}\right)}{u^{\prime \prime}\left(c_{T}\right)^{2}}$.

Proof. Let the marginal utility of consumption at the optimal level of consumption be $z_{t}=u^{\prime}\left(c_{t}^{*}\left(w_{t}\right)\right)$. We define the functions $f_{t}\left(z_{t}\right)$, $g_{t}\left(z_{t}\right)$, and $h_{t}\left(z_{t}\right)$ as the inverse functions of $u^{\prime}, \phi^{\prime}$, and $V^{\prime}$, namely,

$f_{t}\left(z_{t}\right)=\left(u^{\prime}\right)^{-1}\left(z_{t}\right)=c_{t}$,

$g_{t}\left(z_{t}\right)=\left(\phi^{\prime}\right)^{-1}\left(z_{t}\right)=s_{t}$,

and

$h_{t}\left(z_{t}\right)=\left(V^{\prime}\right)^{-1}\left(z_{t}\right)=w_{t}$.

For simplicity, we drop the time subscripts from $f, g$, and $h$. Therefore, we have

$f^{\prime}=\frac{1}{u^{\prime \prime}}, \quad f^{\prime \prime}=-\frac{u^{\prime \prime \prime}}{\left(u^{\prime \prime}\right)^{2}} f^{\prime}=-\frac{u^{\prime \prime \prime}}{\left(u^{\prime \prime}\right)^{3}}$

and

$-\frac{z f^{\prime \prime}}{f^{\prime}}=\frac{u^{\prime \prime \prime} u^{\prime}}{\left(u^{\prime \prime}\right)^{2}}$

Similarly, we get

$-\frac{z g^{\prime \prime}}{g^{\prime}}=\frac{\phi_{t}^{\prime \prime \prime} \phi_{t}^{\prime}}{\left(\phi_{t}^{\prime \prime}\right)^{2}}$

and

$-\frac{z h^{\prime \prime}}{h^{\prime}}=\frac{V_{t}^{\prime \prime \prime} V_{t}^{\prime}}{\left(V_{t}^{\prime \prime}\right)^{2}}$.

However, because $h=f+g, h^{\prime}=f^{\prime}+g^{\prime}$, and $h^{\prime \prime}=f^{\prime \prime}+g^{\prime \prime}$, we obtain

$$
\begin{aligned}
-\frac{z h^{\prime \prime}}{h^{\prime}} & =-z \frac{f^{\prime \prime}+g^{\prime \prime}}{f^{\prime}+g^{\prime}} \\
& =\frac{f^{\prime}}{f^{\prime}+g^{\prime}} \frac{-z f^{\prime \prime}}{f^{\prime}}+\frac{g^{\prime}}{f^{\prime}+g^{\prime}} \frac{-z g^{\prime \prime}}{g^{\prime}} .
\end{aligned}
$$

Note that in the last period of the consumer's life, we have $V_{T}\left(w_{T}\right)=u\left(c_{T}\right)$. Thus, it is obvious that

$\frac{V_{T}^{\prime \prime \prime}\left(w_{T}\right) V_{T}^{\prime}\left(w_{T}\right)}{V_{T}^{\prime \prime}\left(w_{T}\right)^{2}}=\frac{u^{\prime \prime \prime}\left(c_{T}\right) u^{\prime}\left(c_{T}\right)}{u^{\prime \prime}\left(c_{T}\right)^{2}}$.

As for the period $T-1$, because absolute risk tolerance is concave and $\beta_{t} R_{t}>1$, it follows from Lemmas 1 and 2 that

$$
\begin{aligned}
\frac{V_{T-1}^{\prime \prime \prime}\left(w_{T-1}\right) V_{T-1}^{\prime}\left(w_{T-1}\right)}{V_{T-1}^{\prime \prime}\left(w_{T-1}\right)^{2}}= & \frac{f^{\prime}}{f^{\prime}+g^{\prime}} \frac{u^{\prime \prime \prime}\left(c_{T-1}\right) u^{\prime}\left(c_{T-1}\right)}{u^{\prime \prime}\left(c_{T-1}\right)^{2}} \\
& +\frac{g^{\prime}}{f^{\prime}+g^{\prime}} \frac{\phi_{T-1}^{\prime \prime \prime}\left(s_{T-1}\right) \phi_{T-1}^{\prime}\left(s_{T-1}\right)}{\phi_{T-1}^{\prime \prime}\left(s_{T-1}\right)^{2}} \\
= & \frac{f^{\prime}}{f^{\prime}+g^{\prime}}\left(T^{\prime}\left(c_{T-1}\right)+1\right) \\
& +\frac{g^{\prime}}{f^{\prime}+g^{\prime}} \frac{V_{T}^{\prime \prime \prime}\left(w_{T}\right) V_{T}^{\prime}\left(w_{T}\right)}{V_{T}^{\prime \prime}\left(w_{T}\right)^{2}} \\
= & \frac{f^{\prime}}{f^{\prime}+g^{\prime}}\left(T^{\prime}\left(c_{T-1}\right)+1\right)
\end{aligned}
$$




$$
\begin{aligned}
& +\frac{g^{\prime}}{f^{\prime}+g^{\prime}}\left(T^{\prime}\left(c_{T}\right)+1\right) \\
> & T^{\prime}\left(c_{T-1}\right)+1 \\
= & \frac{u^{\prime \prime \prime}\left(c_{T-1}\right) u^{\prime}\left(c_{T-1}\right)}{u^{\prime \prime}\left(c_{T-1}\right)^{2}} .
\end{aligned}
$$

Therefore, inequality ( 7 ) has been proved for $t=T-1$. Similarly, we can prove inequality (7) for $t=T-2, \ldots, 1$.

Now we turn to the proof of Proposition 1.

Proof of Proposition 1. We begin with the proof by defining a function, which yields the amount of savings corresponding to any optimally chosen level of consumption:

$\theta_{t}^{*}\left(c_{t}\right)=w_{t}^{*}\left(c_{t}\right)-c_{t}$,

where $w_{t}^{*}\left(c_{t}\right)$ is the inverse of the optimal consumption rule $c_{t}^{*}\left(w_{t}\right)$.

An alternative definition of $\theta_{t}^{*}\left(c_{t}\right)$ is

$\theta_{t}^{*}\left(c_{t}\right)=g\left(f^{-1}\left(c_{t}\right)\right)$.

Because $w_{t}^{*}\left(c_{t}\right)=\theta_{t}^{*}\left(c_{t}\right)-c_{t}$, it is clear that, if $\theta_{t}^{*}\left(c_{t}\right)$ is convex, $w_{t}^{*}\left(c_{t}\right)$ is also convex. But if $w_{t}^{*}\left(c_{t}\right)$ is convex, $c_{t}^{*}\left(w_{t}\right)$ must be convex, because both are increasing functions. Thus, if we can prove that $\theta_{t}^{*}\left(c_{t}\right)$ is convex, then the consumption rule is concave.

Taking derivatives of $\theta_{t}^{*}\left(c_{t}\right)=g\left(f^{-1}\left(c_{t}\right)\right)$ with respect to $c_{t}$, we have

$\theta_{t}^{* \prime}\left(c_{t}\right)=\frac{g^{\prime}\left(f^{-1}\left(c_{t}\right)\right)}{f^{\prime}\left(f^{-1}\right)}$

and

$$
\begin{aligned}
\theta_{t}^{* \prime \prime}\left(c_{t}\right) & =\frac{\left[g^{\prime \prime}\left(f^{-1}\left(c_{t}\right)\right) f^{\prime}\left(f^{-1}\right)-g^{\prime}\left(f^{-1}\right) f^{\prime \prime}\left(f^{-1}\right)\right] / f^{\prime}\left(f^{-1}\right)}{\left(f^{\prime}\left(f^{-1}\right)\right)^{2}} \\
& =\frac{g^{\prime}\left(f^{-1}\right)}{\left(f^{\prime}\left(f^{-1}\right)\right)^{2}}\left[\frac{g^{\prime \prime}\left(f^{-1}\left(c_{t}\right)\right)}{g^{\prime}\left(f^{-1}\right)}-\frac{f^{\prime \prime}\left(f^{-1}\left(c_{t}\right)\right)}{f^{\prime}\left(f^{-1}\right)}\right] .
\end{aligned}
$$

It follows from Lemma 3 that

$$
\begin{aligned}
\theta_{t}^{* \prime \prime}\left(c_{t}\right) & =\frac{g^{\prime}\left(z_{t}\right)}{f^{\prime}\left(z_{t}\right)^{2}} \frac{1}{z_{t}}\left[\frac{-z_{t} f^{\prime \prime}\left(z_{t}\right)}{f^{\prime}\left(z_{t}\right)}-\frac{-z_{t} g^{\prime \prime}\left(z_{t}\right)}{g^{\prime}\left(z_{t}\right)}\right] \\
& =\frac{g^{\prime}\left(z_{t}\right)}{f^{\prime}\left(z_{t}\right)^{2}} \underbrace{\frac{1}{z_{t}}}_{>0} \underbrace{\left[\frac{u^{\prime \prime \prime}\left(c_{t}\right) u^{\prime}\left(c_{t}\right)}{\left(u^{\prime \prime}\left(c_{t}\right)\right)^{2}}-\frac{V_{t}^{\prime \prime \prime}\left(w_{t}\right) V_{t}^{\prime}\left(w_{t}\right)}{\left(V_{t}^{\prime \prime}\left(w_{t}\right)\right)^{2}}\right]}_{<0} .
\end{aligned}
$$

Therefore, $\operatorname{sign}\left(\theta_{t}^{* \prime \prime}\left(c_{t}\right)\right)=-\operatorname{sign}\left(g^{\prime}\left(z_{t}\right)\right)$.

On the other hand

$g^{\prime}\left(z_{t}\right)=\frac{1}{\phi_{t}^{\prime \prime}\left(s_{t}\right)}$

and

$\phi_{t}^{\prime \prime}\left(s_{t}\right)=\beta_{t+1} R_{t+1} V_{t}^{\prime \prime}\left(w_{t}\right) \leq 0$.

Hence, $\operatorname{sign}\left(g^{\prime}\left(z_{t}\right)\right) \leq 0$ and $\operatorname{sign}\left(\theta_{t}^{* \prime \prime}\left(c_{t}\right)\right) \geq 0$. Therefore, $\theta_{t}^{*}\left(c_{t}\right)$ is convex, which implies that $c_{t}^{*}\left(w_{t}\right)$ is concave.

Remark 1. According to the proof of Proposition 1, it is clear that the optimal consumption rule is strictly concave except for the last period $T$, i.e., $c_{t}^{* \prime \prime}\left(w_{t}\right)<0$ except for $t=T$.

\section{References}

Carroll, C., Kimball, M., 1996. On the concavity of the consumption function. Econometrica 64, 981-992.

Gollier, C., 2001. The Economics of Risk and Time. MIT Press, Cambridge.

Kato, R., Nishiyama, S., 2002. On the Concavity of the Consumption Function with a Quadratic Utility under Liquidity Constraints, Working Paper, Department of Economics, The Ohio State University.

Keynes, J.M., 1936. The General Theory of Employment, Interest, and Money. Harvest, San Diego, New York, London, 1964.

Morris, S., 2002. The Continuous Consumption Rules with Non-exponential Discounting, Working Paper, Yale University.

Zeldes, S.P., 1989. Consumption and liquidity constraints: an empirical investigation. Journal of Political Economy 97, 305-346. 